\title{
POINT: Efficacy of adding mitral valve restrictive annuloplasty to coronary artery bypass grafting in patients with moderate ischemic mitral valve regurgitation: A randomized trial
}

Khalil Fattouch, MD, PhD, Francesco Guccione, MD, Roberta Sampognaro, MD, Gaetano Panzarella, MD, Egle Corrado, MD, Emiliano Navarra, MD, Davide Calvaruso, MD, and Giovanni Ruvolo, MD

Objective: Surgical management of moderate chronic ischemic mitral valve regurgitation is still debated. The aim of this study was to evaluate the effect of adding mitral valve repair to coronary artery bypass grafting on clinical outcomes and left ventricular remodeling in patients who underwent coronary artery bypass grafting alone versus coronary artery bypass grafting plus mitral valve repair in a randomized trial.

Methods: Between February 2003 and May 2007, 102 patients were eligible for this study and were randomly assigned to one of 2 groups by means of card allocation: coronary artery bypass grafting plus mitral valve repair (CABG plus MVR group; 48 patients, $47 \%$ ) or coronary artery bypass grafting alone (CABG group; 54 patients, $53 \%$ ). The 2 groups were similar regarding demographics, perioperative clinical data, and outcomes. There were differences regarding cardiopulmonary bypass $(P<.0001)$ and aortic crossclamp $(P<.0001)$ times. Exercise tests were performed for all survivors to evaluate tolerance to exercise and variability on grade of mitral regurgitation and systolic pulmonary arterial pressure. The study was blinded for physicians and nurses involved in postoperative care and clinical follow-up. The mean follow-up was $32 \pm 18$ months.

Results: Overall in-hospital mortality was 3\% (3 patients). One (1.8\%) patient died in the CABG group, and 2 (4.1\%) patients died in the CABG plus MVR group. Survival rates \pm standard error at 5 years for patients in the CABG and CABG plus MVR groups were $88.8 \% \pm 3.2 \%$ and $93.7 \% \pm 3.1 \%$, respectively. A significant difference was found between the 2 groups with regard to mean New York Heart Association class $(P<.0001)$, left ventricular end-diastolic diameter $(P<.01)$, left ventricular end-systolic diameter $(P<.01)$, pulmonary arterial pressure $(P<.0001)$, and left atrial size $(P<.01)$. At follow-up, coronary artery bypass grafting alone was able to reduce mitral regurgitation grade in $40 \%$ of patients, whereas in the remaining patients mitral regurgitation grade remained stable or worsened. In the CABG group, among the 17 patients with mild mitral regurgitation and 12 patients with moderate mitral regurgitation at rest, $7(40 \%)$ and $9(75 \%)$ patients, respectively, had worsening in mitral regurgitation grade and pulmonary artery pressure during exercise.

Conclusions: The efficacy of adding mitral valve repair to coronary artery bypass grafting is well demonstrated by the improvement of New York Heart Association functional class and percentage of left ventricular ejection fraction and by the decrease of mitral regurgitation grade, left ventricular end-diastolic diameter, left ventricular end-systolic diameter, pulmonary artery pressure, and left atrial size. Moreover, coronary artery bypass grafting alone left more patients with heart failure symptoms at rest and during exercise. Combined coronary artery bypass grafting and mitral valve repair have no effect on survival at short-term follow-up, and the trends that are evident will likely become more significant with time.

Chronic ischemic mitral regurgitation (cIMR) is a functional mitral regurgitation (MR) characterized by a normal leaflet structure and subvalvular apparatus and mostly related to an inferior rather than an anteroseptal myocardial infarction. ${ }^{1}$ According to type IIIb Carpentier's functional classification, ischemic mitral regurgitation (IMR) is the

From the Department of Cardiac Surgery, University of Palermo, Palermo, Italy.

Read at the Eighty-eighth Annual Meeting of The American Association for Thoracic Surgery, San Diego, Calif, May 10-14, 2008.

Received for publication May 2, 2008; revisions received Sept 29, 2008; accepted for publication Nov 7, 2008; available ahead of print June 1, 2009.

Address for reprints: Khalil Fattouch, MD, PhD, University of Palermo, Department

of Cardiac Surgery, Via Liborio Giuffré, 5, 90127 Palermo, Italy (E-mail:

khalilfattouch@hotmail.com).

J Thorac Cardiovasc Surg 2009; 138:278-85

0022-5223/\$36.00

Copyright (c) 2009 by The American Association for Thoracic Surgery

doi: $10.1016 /$ j.jtcvs. 2008.11 .010 consequence of a restricted systolic motion of the leaflets. Leaflet tethering displaces the mitral coaptation rim toward the apex of the left ventricle, causing an incomplete closure of the valve in systole. ${ }^{2,3}$

In the natural history of patients after myocardial infarction, the presence and degree of cIMR are independent risk factors for mortality. ${ }^{4,5}$ Moreover, cIMR in patients with coronary disease is associated with an excess of mortality independently of baseline characteristics and degree of ventricular dysfunction, but the high mortality rate is directly related to the grade of IMR evaluated based on the effective regurgitant orifice area at echocardiographic analysis. ${ }^{6}$

Today there is general agreement that moderate-to-severe to severe (grade 3+ to 4+) cIMR should to be corrected at the time of coronary artery bypass grafting $(\mathrm{CABG}),{ }^{7-9}$ whereas trace-to-mild (grade 1+) cIMR does not require any surgical 

Abbreviations and Acronyms
$\mathrm{CABG}=$ coronary artery bypass grafting
cIMR $=$ chronic ischemic mitral regurgitation
$\mathrm{CPB}=$ cardiopulmonary bypass
IMR = ischemic mitral regurgitation
LVEDD $=$ left ventricular end-diastolic diameter
LVEF = left ventricular ejection fraction
LVESD $=$ left ventricular end-systolic diameter
MR = mitral regurgitation
MVR = mitral valve repair
NYHA $=$ New York Heart Association
PAP $=$ pulmonary artery pressure
TEE $=$ transesophageal echocardiography
TTE $=$ transthoracic echocardiography

treatment. On the other hand, the optimal management of moderate (grade 2+) cIMR is still controversial. ${ }^{10-20}$

Authors advocating mitral valve repair (MVR) at the time of CABG suggest that CABG alone will not correct moderate cIMR in many patients with scarring caused by myocardial infarction and those with annular and ventricular dilatation $^{11,21}$; moreover, significant residual MR after CABG can worsen the prognosis of patients, resulting in late symptoms and decreased long-term survival. ${ }^{5,11,22} \mathrm{Mi}$ tral annuloplasty is nearly always feasible, and it alone will correct moderate cIMR with an operative mortality rate as low as $3 \%$ to $4 \% .{ }^{11,23,24}$ Finally, cIMR is a dynamic condition that is dependent on preload and afterload and can vary in grade with exercise. ${ }^{25,26}$

On the other hand, authors favoring a conservative approach believe that revascularizing ischemic myocardial areas will improve regional wall motion and correct cIMR, ${ }^{12}$ that residual MR after CABG alone does not affect long-term survival or functional status, ${ }^{10,13}$ that the combined approach is associated with high operative mortality rates, ${ }^{27,28}$ and that patients with cIMR tend to have a small left atrium, which makes MVR a demanding procedure.

In this study we aimed to evaluate prospectively the early and midterm results of patients with moderate (grade 2+) cIMR who underwent CABG or CABG plus MVR in a randomized trial.

\section{MATERIALS AND METHODS \\ Patients}

Between February 2003 and May 2007, 132 patients with coronary artery disease and moderate cIMR admitted to our department for CABG were consecutively and prospectively screened for this study. All patients had moderate cIMR caused by restrictive systolic leaflet motion (Carpentier's type IIIb), annular dilation (Carpentier's type I), or both. Patients with a recent myocardial infarction ( $<30$ days), unstable hemodynamic status requiring urgent surgical intervention, concomitant aortic valve operations, organic mitral valve lesions requiring MVR, and requirement for surgical left ventricular restoration were excluded from the study. Finally,
102 patients were eligible for the study and randomly assigned to one of 2 groups: CABG plus MVR (48 patients, $47 \%$ ) or CABG alone (54 patients, $52 \%$ ). Patients were randomized by means of card allocation. Randomization was blinded for intensive care unit and postoperative care staff, including nurses, anesthetists, and cardiologists. This study was also blinded for the cardiologists who performed the clinical follow-up.

The grade of MR was evaluated by using transthoracic echocardiography (TTE) at resting conditions preoperatively and by using transesophageal echocardiography (TEE) intraoperatively. The mean EuroSCOREs were $6.5 \pm 5.1$ and $6.1 \pm 4.8$ for the CABG and CABG plus MVR groups, respectively. Baseline characteristics of the population are presented in Table 1. Each patient signed an informed consent form. The study was approved by the institutional review board of our university.

\section{Clinical Study End Points}

The primary end points of the study were to evaluate the effect of adding MVR to CABG on the clinical status of patients measured based on New York Heart Association (NYHA) functional class and on postoperative reversal of left ventricular remodeling measured based on left ventricular end-systolic diameter (LVESD), left ventricular end-diastolic diameter (LVEDD), and left ventricular ejection fraction (LVEF).

The secondary end point of the study was to assess the tolerability to exercise of all patients in the repair group and of patients in the CABG group with postoperative residual MR of grade $2+$ or less and to evaluate the variability of the MR grade during exercise and its effect on dyspnea and systolic pulmonary artery pressure (PAP).

Moreover, the effect of adding MVR to CABG on early and late mortality and postoperative outcomes was also evaluated.

\section{Surgical Technique}

All surgical procedures were performed through a longitudinal median sternotomy during normothermic cardiopulmonary bypass (CPB) with intermittent antegrade warm blood cardioplegia. All patients underwent conventional multivessel CABG with the use of left internal thoracic artery and saphenous vein grafts. All distal anastomoses were performed during a single aortic crossclamping. The proximal graft anastomoses to the aorta were performed with partial crossclamping of the ascending aorta. After weaning from CPB, the mean graft flow was assessed by mean of Doppler transittime flowmetry for each graft by using a flowmeter (Transonic Systems, Inc, Ithaca, NY). Postoperative intensive care unit management was standardized for all patients.

Mitral valve annuloplasty was performed with a Carpentier-Edwards Physio Ring (Edwards Lifesciences, Irving, Calif). The size of the ring was determined after careful measurement of the height of the anterior leaflet. We measured the height of the A2 segment by means of TEE (transesophageal view at $120^{\circ}$ ), and we chose a prosthetic ring with an anteroposterior diameter of less than 0.8 to $1 \mathrm{~cm}$ with respect to the height of the A2 segment. In this manner we ensured at least $0.8 \mathrm{~cm}$ of the free margin of the anterior leaflet into the surface of coaptation. Rings were inserted by using deep horizontal U sutures with Ti-Cron 2-0 (Syneture, Norwalk, Conn). Surgical data are summarized in Table 2. All patients had intraoperative TEE assessment of the left ventricle and valve function after repair. MVR was considered successful if there was no or trivial residual MR postoperatively. Mean leaflet coaptation height was $8 \pm 3 \mathrm{~mm}$.

\section{Echocardiographic Definition of MR}

Echocardiographic imaging was performed by using standard transthoracic windows with a Hewlett-Packard Sonos 5500 imaging system (Palo Alto, Calif) equipped with a $2.5-\mathrm{MHz}$ transducer. All echocardiographic studies were performed and interpreted by 2 experienced cardiologists. Mitral valve regurgitation was defined as functional IMR when associated with global or regional left ventricular systolic dysfunction with no evidence of primary leaflet, chordal, or papillary muscle pathology. End-systolic and 
TABLE 1. Preoperative patient's characteristics

\begin{tabular}{|c|c|c|c|}
\hline Variables & $\begin{array}{c}\text { CABG group } \\
(\mathbf{n}=54) \\
\end{array}$ & $\begin{array}{l}\text { CABG }+ \text { MVR } \\
\operatorname{group}(n=48)\end{array}$ & $\begin{array}{c}P \\
\text { value }\end{array}$ \\
\hline Age (y) & $66 \pm 7$ & $64 \pm 9$ & .62 \\
\hline Age $>75 y$ & $9(16.5 \%)$ & $7(14.5 \%)$ & .56 \\
\hline Sex (male) & $35(64.8 \%)$ & $30(62.5 \%)$ & .42 \\
\hline Diabetes & $32(59 \%)$ & $28(58.3 \%)$ & .78 \\
\hline COPD & $5(9 \%)$ & $4(8.3 \%)$ & .73 \\
\hline Hypertension & $23(42.5 \%)$ & $26(54 \%)$ & .07 \\
\hline \multicolumn{4}{|l|}{ Previous MI } \\
\hline Anterior & $7(13 \%)$ & $5(10.5 \%)$ & 0.51 \\
\hline Inferior-post-lateral & $44(81.5 \%)$ & $40(83 \%)$ & 0.79 \\
\hline Both & $3(5.5 \%)$ & $3(6.2 \%)$ & .68 \\
\hline Mean NYHA class & $2.4 \pm 1.5$ & $2.3 \pm 1.1$ & .56 \\
\hline Two-vessel disease & $15(27.7 \%)$ & $13(27 \%)$ & .91 \\
\hline Three-vessel disease & $39(72 \%)$ & $35(73 \%)$ & .87 \\
\hline Serum creatinine $>1.5$ & $6(11 \%)$ & $5(10.5 \%)$ & .82 \\
\hline Logistic EuroSCORE & $6.5 \pm 5.1$ & $6.1 \pm 4.8$ & .54 \\
\hline $\operatorname{LVEF}(\%)$ & $43 \pm 9$ & $42 \pm 10$ & .71 \\
\hline LVEF < $35 \%$ & $8(15 \%)$ & $6(12.5 \%)$ & .55 \\
\hline LVEDD (mm) & $58 \pm 7$ & $59 \pm 8$ & .67 \\
\hline LVESD (mm) & $44 \pm 7$ & $45 \pm 8$ & .61 \\
\hline sPAP (mm Hg) & $42 \pm 11$ & $40 \pm 10$ & .53 \\
\hline $\begin{array}{l}\text { Left atrial } \\
\qquad \text { diameter }(\mathrm{mm})\end{array}$ & $38 \pm 7$ & $39 \pm 8$ & .68 \\
\hline Tenting area $\left(\mathrm{cm}^{2}\right)$ & $1.7 \pm 0.7$ & $1.8 \pm 0.6$ & .71 \\
\hline
\end{tabular}

Data are presented as means \pm standard deviation or number (percentage) as shown. CABG, Coronary artery bypass grafting; $M V R$, mitral valve repair; $C O P D$, chronic obstructive pulmonary disease; $M I$, myocardial infarction; NYHA, New York Heart Association; $L V E F$, left ventricular ejection fraction; $L V E D D$, left ventricular enddiastolic dimension; $L V E S D$, left ventricular end-systolic dimension; $\mathrm{s} P A P$, systolic pulmonary arterial pressure.

end-diastolic diameter and volume of the left ventricle and ejection fraction were measured and calculated. Global and regional wall motion abnormalities were evaluated with a 16 -segment model. By using the simplified proximal isovelocity surface area method, the degree of MR was graded as moderate (2+) when the radius of the proximal isovelocity surface area was between 5 and $8 \mathrm{~mm}$. The severity of MR was also evaluated by using the quantitative Doppler method with mitral and aortic stroke volumes.

\section{Clinical and Echocardiographic Follow-up}

All patients were followed up at our outpatient clinic by our cardiologists. Clinical and TTE controls were performed by the same cardiologists who evaluated the population study preoperatively. The physician who performed the clinical follow-up was blinded to study design. Preoperative and postoperative clinical status was determined according to the criteria of NYHA functional class and the Canadian Cardiovascular Society for heart failure and angina, respectively. Follow-up data were obtained in all survivors at 1, 3, and 5 years. Follow-up ended December 30, 2007, and was $100 \%$ complete. The mean follow-up was $32 \pm 18$ months (range, 6-60 months).

Treadmill stress tests and, at the same time, TTE controls were performed at the last follow-up to evaluate clinical status under exercise conditions (evaluated based on appearance of dyspnea, fatigue, and/or angina) and the variability of the grade of MR and systolic PAP. As soon as the treadmill test was interrupted, an echocardiographic examination was performed with the patient in the semisupine position. $\beta$-Blockers were stopped 24 hours before testing. A symptom-limited grade was evaluated. After an initial workload of $25 \mathrm{~W}$ had been maintained for 6 minutes, the workload
TABLE 2. Intraoperative and postoperative patient's data

\begin{tabular}{|c|c|c|c|}
\hline Variables & $\begin{array}{c}\text { CABG group } \\
(\mathbf{n}=\mathbf{5 4}) \\
\end{array}$ & $\begin{array}{l}\text { CABG }+ \text { MVR } \\
\operatorname{group}(n=48) \\
\end{array}$ & $\begin{array}{c}P \\
\text { value }\end{array}$ \\
\hline \multicolumn{4}{|l|}{ Intraoperative data } \\
\hline CPB time (min) & $65 \pm 17$ & $112 \pm 32$ & $<.0001$ \\
\hline $\begin{array}{l}\text { Aortic crossclamp } \\
\text { time (min) }\end{array}$ & $38 \pm 8$ & $88 \pm 19$ & $<.0001$ \\
\hline Grafts per patient & $2.9 \pm 0.5$ & $2.7 \pm 0.6$ & .71 \\
\hline LITA graft & $52(96 \%)$ & $47(98 \%)$ & .82 \\
\hline Use of catecholamines* & $7(13 \%)$ & $8(16.5 \%)$ & .56 \\
\hline IABP support & $1(1.8 \%)$ & $2(4 \%)$ & .12 \\
\hline \multicolumn{4}{|l|}{ Grafts flow (mL/min) } \\
\hline LITA to IVA & $38 \pm 12$ & $36 \pm 18$ & .68 \\
\hline SVG to MO & $45 \pm 16$ & $44 \pm 15$ & .79 \\
\hline SVG to IVP & $48 \pm 11$ & $50 \pm 19$ & .71 \\
\hline \multicolumn{4}{|l|}{ Early outcomes } \\
\hline Bleeding & $2(3.7 \%)$ & $1(2 \%)$ & .15 \\
\hline Renal failure (dialysis) & $2(3.7 \%)$ & $2(4 \%)$ & .81 \\
\hline LCOS & $1(1.8 \%)$ & $1(2 \%)$ & .85 \\
\hline CVA & $1(1.8 \%)$ & 0 & - \\
\hline Pneumonia & 0 & $1(2 \%)$ & - \\
\hline In-hospital mortality & $1(1.8 \%)$ & $2(4 \%)$ & .12 \\
\hline Mechanical ventilation (h) & $21 \pm 6$ & $23 \pm 14$ & .68 \\
\hline ICU stay (d) & $2.5 \pm 1.1$ & $3.0 \pm 1.8$ & .06 \\
\hline Hospital stay (d) & $9.3 \pm 2.8$ & $9.7 \pm 5.1$ & .83 \\
\hline
\end{tabular}

Data are presented as means \pm standard deviation or number (percentage), as shown. $C A B G$, Coronary artery bypass grafting; $M V R$, mitral valve repair; $C P B$, cardiopulmonary bypass; $L I T A$, left internal thoracic artery; IABP, intra-aortic balloon pump; IVA, interventricular anterior artery; $S V G$, saphenous vein graft; $M O$, obtuse marginal ramus; IVP, interventricular posterior ramus; $L C O S$, low cardiac output syndrome; $C V A$, cardiovascular accident; $I C U$, intensive care unit. *Dopamine or dobutamine greater than $5 \mu \mathrm{g} \cdot \mathrm{kg}^{-1} \cdot \mathrm{min}^{-1}$, adrenaline greater than $0.08 \mu \mathrm{g} \cdot \mathrm{kg}^{-1} \cdot \mathrm{min}^{-1}$, or both.

was increased every 3 minutes by $25 \mathrm{~W}$. Blood pressure and a 12-lead electrocardiogram were recorded every 3 minutes. Bidimensional and Doppler echocardiographic recordings were available throughout the test. Exercise was interrupted when ischemic electrocardiographic signs, fatigue, or intolerable dyspnea appeared.

\section{Statistical Analysis}

Numeric values were expressed as means \pm standard deviation. Continuous variables were compared between 2 groups by using Student's unpaired $t$ test. The frequency ratios between 2 groups were compared with the $\chi^{2}$ test. Left ventricular remodeling data were analyzed with the paired $t$ test and the Wilcoxon signed-rank test. Interval-scaled variables, such as age and CPB and aortic crossclamp times, were analyzed by using simple univariate linear regression tests. Actuarial survival and other time-related events were analyzed with the Kaplan-Meier method. The log-rank test was used to compare the statistical significance level.

To calculate the sample size in our study to achieve a power of $90 \%$ (with a difference of 5\%), we used postoperative reversal of remodeling assessed mainly based on LVESD reduction from preoperative to follow-up value. We used LVESD reduction because we believe that it better correlates with postoperative reversal of left ventricular remodeling. In fact, the reduction in LVEDD is not necessary correlated with a reversal of remodeling and improvement in left ventricular function. In case of LVEDD reduction during follow-up, if LVESD remains unchanged or increases, LVEF decreases. On the other hand, if LVESD decreases, LVEF might be unchanged in the case of contemporary LVEDD reduction or even improve if LVEDD remains unchanged. Thus, we believe LVESD is a good tool to assess left ventricular remodeling. 
SPSS statistical software (SPSS, Inc, Chicago, Ill) was used.

\section{RESULTS}

No statistically significant difference was found between the 2 groups according to preoperative demographics and clinical and echocardiographic characteristics. No statistical difference was found between the 2 groups in term of intraoperative data, except for CPB time $(P<.0001)$ and aortic crossclamp time $(P<.0001)$. Data are listed in Tables 1 and 2 .

\section{Early Mortality and Outcome}

The overall in-hospital ( $<30$ days) mortality rate for the entire population was $3 \%$ (3 patients). One (1.8\%) patient died in the CABG group, and $2(4 \%)$ patients died in the CABG plus MVR group. Causes of in-hospital death were low cardiac output in 2 patients and multiorgan failure in 1 patient.

\section{Late Mortality and Outcome}

Follow-up was completed in all survivors, with a mean duration of $32 \pm 18$ months. Late death occurred in 5 $(9.5 \%)$ patients in the CABG group and in $1(2 \%)$ patient in the CABG plus MVR group. The cumulative survival rate for both groups, including in-hospital mortality, is shown in Figure 1; no statistically significant difference was found between the 2 groups. Survival rates \pm standard error for patients in the CABG group were $98.1 \% \pm 2 \%$, $92.6 \% \pm 2.8 \%$, and $88.8 \% \pm 3.2 \%$ at 1,3 , and 5 years, respectively. Survival rates \pm standard error for patients in the CABG plus MVR group were $95.8 \% \pm 2.3 \%$ at 1 year and 3 years and $93.7 \% \pm 3.1 \%$ at 5 years.

In the CABG group causes of late death were heart failure in 3 patients (among whom 1 patient died during reoperation on the mitral valve for severe MR with progressive left ventricular dilatation after readmission for congestive heart failure), arrhythmia in 1 patient, and sudden death in 1 patient. In the CABG plus MVR group sudden late death occurred in 1 patient with an LVEF of less than $35 \%$ and an LVEDD of $68 \mathrm{~mm}$.

\section{Effect on Postoperative MR and NYHA Class}

Patients in the CABG plus MVR group had no late recurrent MR of greater than grade $1+$. Among the $4(8.3 \%)$ patients with trivial postoperative residual MR, 1 died 33 months after the operation, and in the other 3 patients, the MR grade remained stable during follow-up. In the CABG group $40(75.5 \%)$ patients had moderate postoperative MR, and $13(24.5 \%)$ patients had mild MR at hospital discharge and at the first month's control visit. At the last follow-up, trivial MR was present in $2(4 \%)$ patients, mild MR was present in $17(36 \%)$ patients, moderate MR was present in $12(25 \%)$ patients, and moderate-to-severe MR was present in $17(35 \%)$ patients. These data suggest that

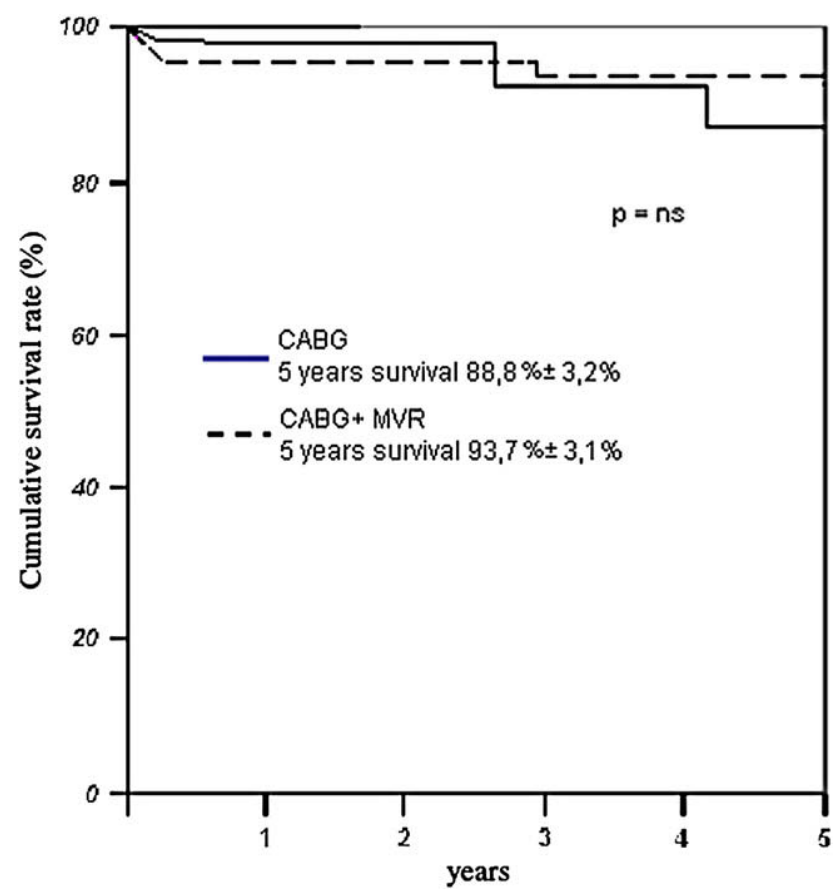

FIGURE 1. Cumulative survival curves for both groups. $C A B G$, Coronary artery bypass grafting; $M V R$, mitral valve repair.

CABG alone left $25 \%$ of patients in moderate MR, and in $35 \%$ of patients, the grade of MR worsened, from moderate to moderate-to-severe. The time-related evolution of postoperative residual MR during follow-up is shown in Figure 2.

In the CABG group NYHA class improved from $2.2 \pm$ 1.5 to $1.6 \pm 0.6(P=.02)$, but in the $\mathrm{CABG}$ plus MVR group it improved from $2.3 \pm 1.1$ to $0.6 \pm 0.8(P<.0001$, Table 3$)$. At the last follow-up, NYHA class II or greater was present in $21(43.7 \%)$ patients in the CABG group and in $7(15.5 \%)$ patients in the CABG plus MVR group $(P=0.002)$.

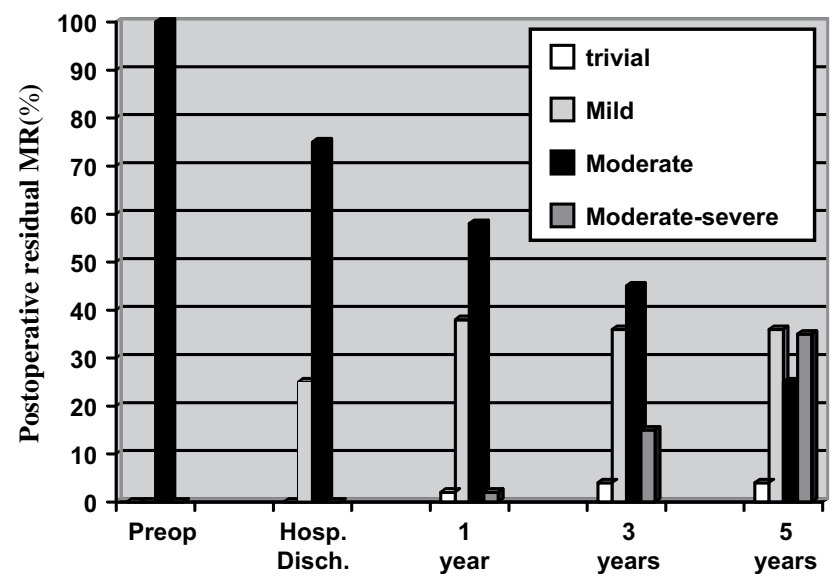

FIGURE 2. Residual postoperative mitral regurgitation $(M R)$ in the coronary artery bypass grafting group during follow-up. 
TABLE 3. Clinical and echocardiographic follow-up data in all survivors

\begin{tabular}{|c|c|c|c|c|c|c|}
\hline & \multicolumn{3}{|c|}{ CABG group $(n=48)$} & \multicolumn{3}{|c|}{ CABG + MVR group $(n=45)$} \\
\hline & Baseline & Follow-up & $P$ value & Baseline & Follow-up & $P$ value \\
\hline LVEDD (mm) & $58 \pm 7$ & $56 \pm 8$ & NS & $59 \pm 8$ & $52 \pm 7 *$ & $<.001$ \\
\hline LVESD (mm) & $44 \pm 7$ & $42 \pm 8$ & NS & $45 \pm 8$ & $37 \pm 5^{*}$ & $<.001$ \\
\hline LVEF $(\%)$ & $43 \pm 9$ & $45 \pm 7$ & NS & $42 \pm 10$ & $48 \pm 8$ & $<.001$ \\
\hline sPAP (mm Hg) & $42 \pm 11$ & $38 \pm 12$ & NS & $40 \pm 10$ & $26 \pm 5 \dagger$ & $<.0001$ \\
\hline Left atrial size (mm) & $38 \pm 7$ & $44 \pm 8$ & $<.001$ & $39 \pm 8$ & $36 \pm 3^{*}$ & NS \\
\hline Tenting area $\left(\mathrm{cm}^{2}\right)$ & $1.7 \pm 0.7$ & $1.8 \pm 0.3$ & NS & $1.8 \pm 0.6$ & $1.1 \pm 0.3^{*}$ & $<.001$ \\
\hline Mean NYHA class & $2.2 \pm 1.5$ & $1.6 \pm 0.6$ & .002 & $2.3 \pm 1.1$ & $0.6 \pm 0.8 \dagger$ & $<.0001$ \\
\hline Mean MR grade & 2 & $1.7 \pm 0.6$ & NS & 2 & $0.08 \pm 0.2 \dagger$ & $<.0001$ \\
\hline
\end{tabular}

Data are presented as means \pm standard deviation or number (\%), as shown. $C A B G$, Coronary artery bypass grafting; $M V R$, mitral valve repair; $L V E D D$, left ventricular end-diastolic dimension; $L V E S D$, left ventricular end-systolic dimension; $L V E F$, left ventricular ejection fraction; $s P A P$, systolic pulmonary artery pressure; $N Y H A$, New York Heart Association functional class; $M R$, mitral regurgitation. ${ }^{*} P<.01$ versus the CABG group. $\dagger P<.0001$ versus the CABG group.

\section{Echocardiographic Results}

Follow-up TTE analysis was performed in all survivors in both groups. MR grade was improved in all patients $(100 \%)$ in the CABG plus MVR group compared with $19(40 \%)$ patients in the CABG group $(P<.0001)$. Reversal in left ventricular remodeling measured by change in LVEDD $(P<.001)$, LVESD $(P<.001)$, and LVEF $(P<.001)$ was significantly observed in the CABG plus MVR group with respect to baseline values, but no statistically significant difference in left ventricular reversal remodeling was observed in the CABG group. Moreover, LVEDD $(P<.01)$ and LVESD $(P<.01)$ were more decreased in the CABG plus MVR group versus that seen in the CABG group. In the CABG plus MVR group we found an improvement in systolic PAP at follow-up with respect to patients in the CABG group $(P<.0001)$ and to baseline values $(P<$ $.0001)$. The left atrial size changed from $39 \pm 8$ to $37 \pm 3$ $\mathrm{mm}$ in the CABG plus MVR group and from $38 \pm 6$ to 44 $\pm 8 \mathrm{~mm}(P<.001)$ in the CABG group. The tenting area at follow-up decreased significantly in patients in the $\mathrm{CABG}$ plus MVR group with respect to the $\mathrm{CABG}$ group $(P<.0001)$ and baseline values $(P<.001)$. Data are presented in Table 3.

TTE analysis during exercise was performed in all patients in the CABG plus MVR group and in $31(65 \%)$ patients in the CABG group, excluding those with residual moderate-to-severe MR (17 patients). We analyzed the clinical status of patients during a treadmill test (based on onset of symptoms, such as dyspnea, fatigue, and angina), the modification of the grade of MR, and the worsening of PAP. Data from the echocardiographic analysis during exercise condition are shown in Figure 3. Among the 17 patients with mild MR at rest, $10(60 \%)$ showed a stable MR grade during exercise, but in $7(40 \%)$ patients the MR grade changed from mild to moderate, with worsening in systolic PAP and without symptom appearance. Among the 12 patients with moderate MR at rest, only $3(25 \%)$ remained with the same MR grade without symptoms, but in the other $9(75 \%)$ patients, the MR grade changed from moderate to moderate-to-severe, and the exercise test was stopped because of the appearance of dyspnea. No patient had chest pain, significant ischemic electrocardiographic changes, or arrhythmia. In the CABG plus MVR group 3 patients stopped the exercise test for fatigue, and 42 patients complete the exercise test without the appearance of dyspnea or modification of MR grade.

\section{DISCUSSION}

The effect on early and long-term outcome of moderate cIMR in patients presenting for CABG is controversial. Clinical studies provide only limited information about the dilemma to treat or not to treat moderate cIMR. ${ }^{10-20,24}$ This conflicting decision is mainly affected by the lack of prospective studies and by the comparison of outcome in dissimilar patient groups. ${ }^{10-13}$ In this randomized study we aimed to evaluate the effect of mitral valve annuloplasty in patients undergoing CABG with moderate cIMR and its effect on outcomes in terms of mortality, postoperative NYHA functional class, and left ventricular remodeling compared with $\mathrm{CABG}$ alone.

Authors favoring a conservative approach believe that CABG alone can be sufficient to obtain a reduction in MR postoperatively and to improve clinical symptoms. These authors suggest that myocardial revascularization alone, restoring a good myocardial perfusion, leads to an enhancement of left ventricular segmental and global kinesia, to a reduction in left ventricular dimensions, and finally to a significant reduction in MR because of restored valvular function. We believe that these findings are partially true because in many patients with scarce area of myocardium after infarction, CABG could not be effective in myocardial functional improvement, left ventricular remodeling can be maintained, and postoperative reversal remodeling is not predictable.

Duarte and colleagues ${ }^{13}$ showed that the late survival of patients with coronary artery disease and preoperative IMR undergoing CABG alone was similar to that of a matched control group of patients with only coronary 


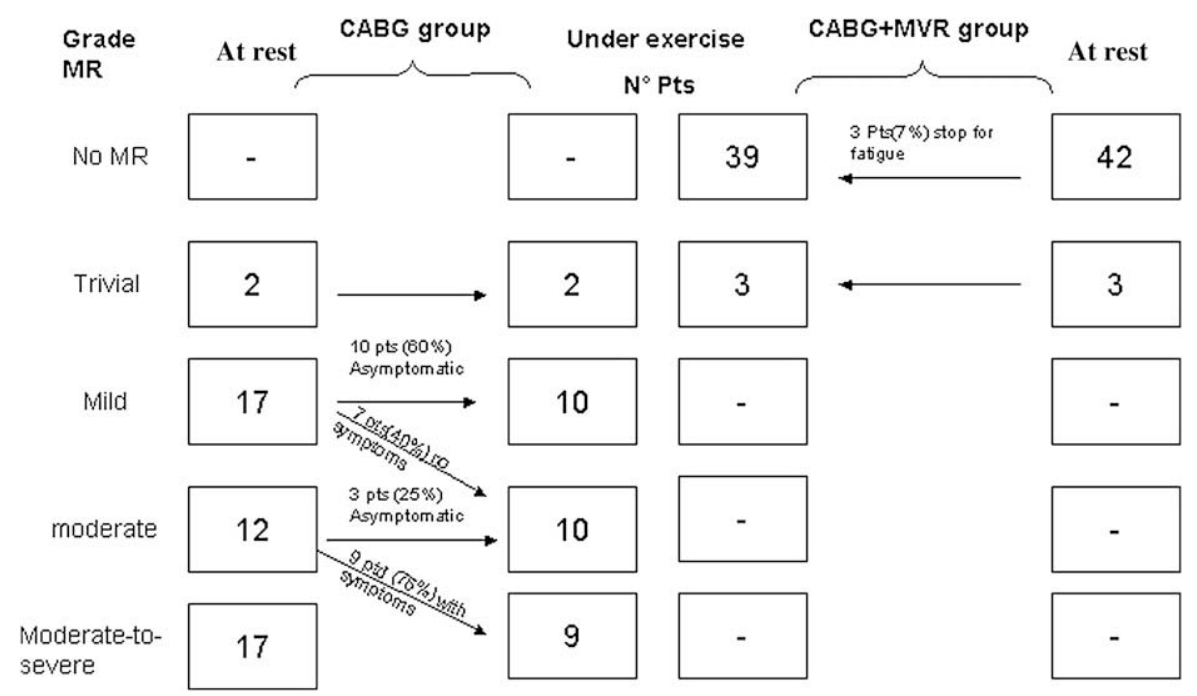

FIGURE 3. Changes in mitral regurgitation $(M R)$ grade during stress testing. $C A B G$, Coronary artery bypass grafting; $M V R$, mitral valve repair; $P t s$, patients.

artery disease undergoing CABG. Although no postoperative determination of residual MR was performed in the Duarte and colleagues study, the equivalent operative mortality and long-term survival rates (mean follow-up, 4.3 years) led them to conclude that moderate IMR at the time of revascularization does not always warrant operative correction.

Tolis and associates ${ }^{15}$ showed that isolated CABG was sufficient to treat mild-to-moderate IMR and advanced ischemic cardiomyopathy. They observed an improvement in ejection fraction (mean from $22 \%$ to $31.5 \%$ ) and NYHA class, a good effect on MR (often disappeared), and a good long-term survival $(88 \%$ at 1 year, $65 \%$ at 3 years, and $50 \%$ at 5 years). Kim and coworkers ${ }^{16}$ showed that combined MVR and CABG lead to similar 5-year survivals when compared with CABG alone $(44 \% \pm 5 \%$ vs $52 \% \pm 5 \%$ ).

On the other hand, Lam and colleagues ${ }^{17}$ from the Cleveland Clinic found that moderate IMR was not treated with CABG alone and was associated with reduced survival in patients with moderate IMR compared with patients undergoing matched bypass without moderate IMR (5-year survival, $73 \%$ vs $85 \%, P=.003$ ).

Our data do not demonstrate a positive effect on early and late survival of adding valve repair to $\mathrm{CABG}$ with respect to CABG alone, which is in accordance with previous studies. ${ }^{13-16,18}$ However, this study was not powered to detect differences in survival.

Despite the fact that adding valve repair to $\mathrm{CABG}$ did not increase survival, its efficacy in the improvement of postoperative NYHA class and on reversal of LV remodeling was well demonstrated. Functional NYHA class changed from $2.2 \pm 1.5$ to $1.6 \pm 0.6(P=.002)$ and from $2.3 \pm 1.1$ to $0.6 \pm 0.8(P<.0001)$ in the CABG and CABG plus
MVR groups, respectively. These data suggest that CABG alone was less effective in improving NHYA class in patients with ischemic heart disease and concomitant moderate cIMR with respect to CABG plus MVR $(P<.0001$, Figure 3). Our results are in contrast with results reported by Kim and coworkers, ${ }^{16}$ who observed a similar improvement in NYHA class at 2-year follow-up in their revascularization (from $3.12 \pm 1$ to $1.12 \pm 0.38$ ) and repair (from $3.22 \pm 0.82$ to $1.29 \pm 0.63$ ) groups.

Moreover, we found that patients undergoing MVR had improved LVEDD $(P<.001)$, LVESD $(P=.001)$, and LVEF $(P<.001)$ with respect to baseline values, and LVEDD $(P<.01)$ and LVESD $(P<.01)$ were significantly decreased with respect to values in the CABG group. Our data are in agreement with the work of Kim and coworkers ${ }^{16}$ and Kang and associates, ${ }^{18}$ who found reversed left ventricular remodeling in patients who underwent combined MVR and CABG. However, it is not clear whether improvements in ischemic MR caused by MVR can have favorable effects on left ventricular remodeling. We suggest that adding MVR to $\mathrm{CABG}$ can abolish the regurgitant volume through the mitral valve and preserve the left ventricle from volume overloading, which can contribute to long-term left ventricular remodeling, despite the efficacy of myocardial revascularization.

Left ventricular reverse remodeling has been previously observed after restrictive mitral annuloplasty. ${ }^{21}$ Some authors suggested that in patients with IMR undergoing CABG alone, the severity of MR and left ventricular function can improve because revascularization might lead to left ventricular functional recovery with restoration of valve coaptation. ${ }^{15}$ In other series of patients without postoperative left ventricular functional recovery, MVR reduced the grade of MR more significantly than CABG alone because 
of a reduction in mitral annulus area caused by ring annuloplasty and improvement in the leaflet coaptation surface independently of left ventricular functional recovery. ${ }^{18-21}$ Because postoperative improvement of left ventricular function with revascularization alone cannot be predicted reliably and the reversal of left ventricular remodeling was widely observed after restrictive mitral annuloplasty, we suggest use of the combination of CABG and MVR to treat cIMR.

Our results are consistent with the work of Lam and colleagues, ${ }^{17}$ who found that moderate cIMR was not treated properly with CABG alone and is associated with reduced survival, and with the work of Aklog and coworkers, ${ }^{11}$ who observed that CABG alone left many patients with residual postoperative MR whereas mitral valve restrictive annuloplasty resulted in the ideal approach, at least for patients with annular dilatation.

The effect of postoperative cIMR on systolic PAP and on left atrial size is still unclear, and few have investigated this issue. In our series systolic PAP decreased from $42 \pm 11$ to $38 \pm 12 \mathrm{~mm} \mathrm{Hg}$ in the CABG group and from $40 \pm 10$ to 26 $\pm 5 \mathrm{~mm} \mathrm{Hg}(P<.0001)$ in the CABG plus MVR group (Table 3). At follow-up, left atrial size decreased significantly in the CABG plus MVR group versus that seen in the CABG group $(P<.01)$. Left atrial size remained nearly unchanged compared with baseline values in patients who had MVR but increased in patients undergoing CABG alone (from $38 \pm 7$ $\mathrm{mm}$ to $44 \pm 8 \mathrm{~mm}, P<.001$ ). This could be related to the fact that in the CABG group the grade of MR was worsened during follow-up in $35 \%$ of patients and was still unchanged in $25 \%$ of patients. Moreover, we observed that the left atrial size was also increased in patients with postoperative trivialto-mild MR, probably because of the dynamic nature of IMR, which could change in severity under different loading condition.

Today it is evident from several studies ${ }^{5,6,11,19}$ that cIMR is related to an adverse prognosis, and the high mortality rate observed in such patients is related not only to its presence but also more importantly to the grade of MR. However, the evaluation of cIMR only under resting conditions might underestimate the full effect of the lesion and its clinical effects. Indeed, cIMR is a dynamic lesion, and its severity can vary over time. Lebrun and associates ${ }^{25}$ and Lancellotti and colleagues ${ }^{26}$ showed that exercise-induced changes in regurgitant volume and in systolic pulmonary pressure were larger in patients who stopped their exercise for dyspnea compared with those who stopped for fatigue. A large exercise-induced increase in cIMR, in particular an increase in effective regurgitant orifice of $13 \mathrm{~mm}^{2}$ or greater, is associated with increased mortality and morbidity, hospital admission for worsening heart failure, and major cardiac events. This observation suggests a need for a better understanding of the dynamics of residual postoperative mild-to-moderate MR and its effect on clinical outcome in patients who under- went only CABG. Furthermore, in this subgroup of patients, we performed an echocardiographic control during a bicycle exercise test to evaluate changes in the grade of MR, changes in PAP, and symptoms.

During exercise, we showed that the $75 \%$ of patients with moderate MR at rest had worse MR with congestive heart failure symptoms, and $40 \%$ of patients with mild MR at rest saw a change in MR grade from mild to moderate with worsening in PAP without symptom appearance (Figure 3). Our results indicated that many patients who underwent $\mathrm{CABG}$ alone with residual mild-to-moderate MR at rest had more severe MR during different loading conditions, which can contribute to symptom appearance and an increase in systolic PAP and left atrial size. This could lead to new onset of atrial fibrillation with poor long-term prognosis. Furthermore, we believe that in these patients future investigation must accurately address which patients will have postoperative worsening in MR grade and congestive heart failure symptoms despite the MR grade at rest.

\section{CONCLUSIONS}

Our primary end point was achieved, and the efficacy of adding MVR to CABG is well demonstrated by the improvement of NYHA functional class and LVEF and by the decrease in LVEDD and LVESD.

There was no effect on early and long-term survival if MVR was added to CABG in patients with coronary artery disease and moderate cIMR. However, our 32-month average follow-up is short, and the trends that are evident will likely become more significant with time.

The combined approach was also found to be effective in reducing systolic PAP and left atrial size with respect to CABG alone, which left more patients with heart failure symptoms. Moreover, the $35 \%$ of patients who underwent CABG alone have worsened in MR grade at follow-up (moved from grade $2+$ to $3+$ ), and the $75 \%$ (9 patients) of patients with stable moderate MR (grade $2+$ ) at rest move to moderate-to-severe MR (grade $3+$ ) with appearance of dyspnea under exercise conditions.

\section{References}

1. Kumanohoso T, Otsuji Y, Yoshifuku S, Matsukida K, Koriyama C, Kisanuki A, et al. Mechanism of higher incidence of ischemic mitral regurgitation in patients with inferior myocardial infarction: quantitative analysis of left ventricular and mitral valve geometry in 103 patients with prior myocardial infarction. $J$ Thorac Cardiovasc Surg. 2003; 125:135-43.

2. Tibayan FA, Rodriguez F, Zasio MK, Bailey L, Liang D, Daughters GT, et al. Geometric distorsion of the mitral valvular-ventricular complex in chronic ischemic mitral regurgitation. Circulation. 2003;108(suppl II):II116-21.

3. Yu HY, Su MY, Liao TY, Peng HH, Lin FY, Tseng WY. Functional mitral regurgitation in chronic ischemic coronary artery disease: analysis of geometric alterations of mitral apparatus with magnetic resonance imaging. J Thorac Cardiovsc Surg. 2004;128:543-51.

4. Tcheng JE, Jackman JD Jr, Nelson CL, Gardner LH, Smith LR, Rankin JS, et al. Outcome of patients sustaining acute ischemic mitral regurgitation during myocardial infarction. Ann Intern Med. 1992;117:18-24. 
5. Hickey MS, Smith LR, Muhlbaier LH, Harrell FE Jr, Reves JG, Hinohara T, et al. Current prognosis of ischemic mitral regurgitation. Circulation. 1988;78(suppl): I51-9.

6. Grigioni F, Enriquez-Sarano M, Zehr KJ, Bailey KR, Tajik AJ. Ischemic mitral regurgitation. Long-term outcome and prognostic implications with quantitative Doppler assessment. Circulation. 2001;103:1759-64.

7. Enriquez-Sarano M. Timing of mitral valve surgery. Heart. 2002;87:79-85.

8. Gillinov AM, Wierup PN, Blackstone EH, Bishay ES, Cosgrove DM, White J, et al. Is repair preferable to replacement for ischemic mitral regurgitation? J Thorac Cardiovasc Surg. 2001;122:1125-41.

9. Miller DC. Ischemic mitral regurgitation redux - to repair or to replace? J Thorac Cardiovasc Surg. 2001;122:1059-62.

10. Arcidi JM Jr, Hebeler RF, Craver JM, Jones EL, Hatcher CR Jr, Guyton RA. Treatment of moderate mitral regurgitation and coronary disease by coronary bypass alone. J Thorac Cardiovasc Surg. 1988;95:951-9.

11. Aklog L, Filsoufi F, Flores KQ, Chen RH, Cohn LH, Nathan NS, et al. Does coronary artery bypass grafting alone correct moderate ischemic mitral regurgitation? Circulation. 2001;104(suppl):I68-75.

12. Christenson JT, Simonet F, Bloch A, Maurice J, Velebit V, Schmuziger M. Should a mild to moderate ischemic mitral valve regurgitation in patients with poor left ventricular function be repaired or not? J Heart Valve Dis. 1995;4:484-8.

13. Duarte IG, Shen Y, MacDonald MJ, Jones EL, Craver JM, Guyton RA. Treatment of moderate mitral regurgitation and coronary disease by coronary bypass alone: late results. Ann Thorac Surg. 1999;68:426-30.

14. Ryden T, Bech-Hanssen O, Brandrup-Wognsen G, Nilsson F, Svensson S, Jeppsson A. The importance of grade 2 ischemic mitral regurgitation in coronary artery bypass grafting. Eur J Cardiothorac Surg. 2001;20:276-81.

15. Tolis GA Jr, Korkolis DP, Kopf GS, Elefteriades JA. Revascularization alone (without mitral valve repair) suffices in patients with advanced ischemic cardiomyopathy and mild-to-moderate mitral regurgitation. Ann Thorac Surg. 2002; 74:1476-81.

16. Kim YH, Czer LS, Soukiasian HJ, De Robertis M, Magliato KE, Blanche C, et al. Ischemic mitral regurgitation: revascularization alone versus revascularization and mitral valve repair. Ann Thorac Surg. 2005;79:1895-901.
17. Lam BK, Gillinov AM, Blackstone EH, Rajeswaran J, Yuh B, Bhudia SK, et al. Importance of moderate ischemic mitral regurgitation. Ann Thorac Surg. 2005;79: 462-70.

18. Kang DH, Kim MJ, Kang SJ, Song JM, Song H, Hong MK, et al. Mitral valve repair versus revascularization alone in the treatment of ischemic mitral regurgitation. Circulation. 2006;114(suppl):I499-503.

19. Di Mauro M, Di Giammarco G, Vitolla G, Contini M, Iacò AL, Bivona A, et al. Impact of no-to-moderate mitral regurgitation on late results after isolated coronary artery bypass grafting in patients with ischemic cardiomyopathy. Ann Thorac Surg. 2006;81:2128-34.

20. Filsoufi F, Aklog L, Byrne JG, Cohn LH, Adams DH. Current results of combined coronary artery bypass grafting and mitral annuloplasty in patients with moderate ischemic mitral regurgitation. J Heart Valve Dis. 2004;13:747-53.

21. Bax JJ, Braun J, Somer ST, Klautz R, Holman ER, Versteegh MI, et al. Restrictive annuloplasty and coronary revascularization in ischemic mitral regurgitation results in reverse left ventricular remodelling. Circulation. 2004;110(suppl II):II103-8.

22. Adler DS, Goldman L, O'Neil A, Cook EF, Mudge GH Jr, Shemin RJ, et al. Longterm survival of more than 2,000 patients after coronary artery bypass grafting. Am J Cardiol. 1986;58:195-202.

23. Czer LS, Maurer G, Trento A, De Robertis M, Nessim S, Blanche C, et al. Comparative efficacy of ring and suture annuloplasty for ischemic mitral regurgitation. Circulation. 1992;86(suppl):II46-52.

24. Adams DH, Chen RH, Byrne JG, Filsoufi F, Cohn LH, Aklog L, et al. Improving outcomes in patients with moderate ischemic mitral regurgitation undergoing combined CABG and mitral annuloplasty. Circulation. 2000;102(suppl II):II462.

25. Lebrun F, Lancellotti P, Pierad LA. Quantitation of functional mitral regurgitation during bicycle exercise in patients with heart failure. J Am Coll Cardiol. 2001;38 1685-92.

26. Lancellotti P, Gerard P, Pierad P. Long term outcome of patients with heart failure and dynamic mitral regurgitation. Eur Heart J. 2005;26:1528-32.

27. Dion R, Benetis R, Elias B, Guennaoui T, Raphael D, Van Dyck M, et al. Mitral valve procedures in ischemic regurgitation. J Heart Valve Dis. 1995;4(suppl 2):S124-9.

28. Braun J, van de Veire NR, Klautz RJ, Versteegh MI, Holman ER, Westenberg JJ, et al. Restrictive mitral annuloplasty cures ischemic mitral regurgitation and heart failure. Ann Thorac Surg. 2008;85:430-7. 